\title{
Peningkatan Kemampuan Bahasa Inggris Siswa Kelas III SMA Islam Terpadu Al-Kamal NW dengan Metode Audio-Visual
}

\author{
Sutarman ${ }^{1}$, Zainudin Abdussamad ${ }^{2}$, Abdul Muhid ${ }^{3}$, Lela Rahmawati ${ }^{4}$, Wahyu Kamil \\ Syarifaturrahman ${ }^{5}$ \\ sutarman@universitasbumigora.ac.id ${ }^{1}$, samadzain12@gmail.com², \\ abdulmuhid@universitasbumigora.ac.id², lelarahmawati133@gmail.com \\ wahyu.kamil@universitasbumigora.ac.id ${ }^{5}$ \\ 1,2,3,4,5 Universitas Bumigora
}

\section{Article History:}

Received: 18-06-2021

Revised: 26-06-2021

Accepted : 12-07-2021
Keywords: English Training, AudioVisual, SMA IT A-Kamal NW

\begin{abstract}
This service activity aims at training the English ability of the third grade students of SMA Islam Terpadu AlKamal NW in Narmada. This service is to solve the lack of human sources in English teachers in this school in which the headmaster plans to encourage students' ability in English speaking. It is conducted for three months started from March to May in 2021. To implement the service, the team makes some stages consisting of planning, coordination, preparation, training, and evaluation. In training, the audio-visual method is used to increase the students' ability in mastering English. The results shows that the average score of all students are 74 for pronunciation, 73 for fluency and 72.94 for grammar. The average score indicate that their ability in English mastery is quite good and need to be developed for further. Thus, team expects that this service run continuously and get supports from related stakeholders.
\end{abstract}

\section{Pendahuluan}

Dosen merupakan salah satu unsur dalam dunia pendidikan di Indonesia. Dosen memiliki peran utama yang biasa disebut Tridharma perguruan Tinggi. Tridharma Perguruan tinggi ini terdiri dari Pengajaran, Penelitian dan Pengabdian. Ketiga tugas ini harus dilakukan oleh dosen dalam setiap semester. Dalam pengajaran, dosen mengajar mata kuliah dengan beban maksimal 12 SKS dalam setiap semester, dan dalam penelitian dosen juga diwajibkan untuk melakukan penelitian dan menelurkan hasil penelitian itu ke dalam jurnal ilmiah baik dalam negeri ataupun luar negeri. Sedangkan pengabdian, dosen harus melakukan pengabdian kepada masyarakat dengan tujuan sebagai bentuk sumbangsih keilmuan dosen agar manfaatnya bisa dirasakan oleh masyarakat luas.

Artikel ini merupakan artikel pengabdian yang dilakukan di SMA Islam terpadu AlKamal NW. Sekolah ini merupakan sekolah swasta yang bernaung dibawah Kemendikbud dan di bawah Yayasan 17 Ramadhan. Sekolah ini tergolong baru karena resmi memperoleh ijin sekitar pada tahun 2011 sehingga sangat membutuhkan bantuan SDM untuk meningkatkan mutu pendidikan di lingkungan sekolah. Sekolah ini berlokasi di Jl. Negara, KM. 15 Tibupiling, Kec. Narmada, Kabupaten Lombok Barat. Saat ini, SMA Islam Terpadu Al-Kamal NW memiliki jumlah siswa sekitar 85 siswa di bagi menjadi 3 rombel dengan guru 
sekitar 12 orang.

Sekolah ini juga mengadops sistem kepondokan dimana semua siswa diwajibkan untuk tinggal di Pondok Pesantren agar kegiatan siswa dapat dikontrol dengan baik. Dengan sistem kepondokan, sekolah ini memiliki banyak kegiatan regular maupun ekstrakurikuler. Kegiatan regular berupa kegiatan sekolah resmi dengan menggunakan kurikulum 2013 dan Madrasah Diniyah dengan orientasi mengaji ilmu-ilmu agama. Madrasah diniayah ini juga diwajibkan kepada semua siswa dan memiliki jadwal resmi seperti jadwal kegiatan sekolah. Kegiatan resmi ini dimulai dari jam 07.30 dan berakhir pada jam 12.30 untuk kegiatan sekolah sedangkan madrasah diniyah dimulai dari jam 02.00 sampai dengan jam 03.00. untuk kegiatan non regular atau ekstrakurikuler, sekolah ini memiliki berbagai macam kegiatan seperti pencak silat, grup sepak bola, grup hadrah, dan masih banyak lagi kegiatan -kegiatan lain yang sangat menunjang keahlian siswa.

SMA Islam terpadu Al-Kamal NW memiliki fasilitas gedung yang cukup memadai namun belum memiliki fasilitas pendukung pembelajaran seperti laboratorium, dan multimedia. Selain itu, SDM yang kurang membuat pembelajaran di sekolah kurang maksimal sehingga kemampuan siswa dalam bahasa Inggris masih minim. Dengan pengabdian ini, diharapkan akan ada perubahan dan perbaikan dalam hal keterampilan bahasa inggris bagi siswa -siswa SMA Islam terpadu Al-Kamal NW.

Pengabdian ini bertujuan untuk meningkatkan kemampuan bahasa Inggris Siswa SMA Islam Terpadu Al-Kamal NW dengan menggunakan metode Audio-Visual. Metode ini dipilih karena penggunaan dua indera yakni indra pendengaran dan indra penglihatan. Dengan menggabungkan kedua indra ini, kemampuan siswa menangkap materi ajar akan jauh lebih baik (Abdussamad et al., 2021). Hal ini sesuai dengan yang diungkap oleh Fitria (2014) dalam penelitiannya tentang penggunaan metode audio-visual dalam pembelajaran pada anak usia dini.

Metode audio-Visual merupakan metode yang menerapkan penggunaan media dalam proses pembelajaaran. Media tersebut dapat berupa media tradisional maupun modern. Media tradisional yaitu media yang dibuat secara manual oleh guru sedangkan media modern adalah media yang dibuat menggunakan teknologi canggih seperti LCD, Komputer, laptop dll. Menurut Hermawan \& H, (2009), media adalah teknologi pembawa pesan yang dapat dimanfaatkan untuk keperluan pembelajaran. Dengan demikian, Media pembelajaran adalah alat yang digunakan untuk menyampaikan pesan pembelajaran dari seorang guru kepada siswa.

Penggunaan media tentunya memiliki tujuan, bersumber dari Sanaky (2011) menyatakan bahwa penggunaan media sebagai alat bantu ajar memiliki beberapa tujuan:

1. Mempermudah proses pembelajaran di kelas

2. Meningkatkan efisiensi proses pembelajaran

https://journal.universitasbumigora.ac.id/index.php/ADMA

E-ISSN: 2723-7370 
3. Menjaga relevansi antara materi dengan tujuan belajar

4. Membantu konsentrasi pembelajar dalam proses pembelajaran

Selain itu, Dia juga menambahkan bahwa pemebelajaran dengan media akan jauh lebih menarik bagi siswa dari pada tidak menggunakan media. Hal ini karena media menarik perhatian siswa sehingga banyak aktifitas yang terlibat seperti mengamati, melakukan, mendemostrasikan, dan lain-lain (Rahmawati \& Sutarman, 2021). Dengan demikian, siswa akan lebih bermotivasi dalam mengikuti proses pembelajaran karena makna penyampaian dengan media akan lebih jelas dan siswa tidak merasa bosan dengan materi yang menarik.

Kembali ke media audio visual, Anderson (1994) berpendapat bahwa media audio visual sebagai media pembelajaran merupakan rangkain gambaran elektronis yang memiliki unsur suara dan dan gambar yang dituangkan dalam video yang kemudian diputar dalam proses pembelajaran. Media audio visual memiliki beberapa tujuan dalam penggunaannya sebagai media pembalajaran, di antaranya yakni untuk mengembangkan kemampuan koginitif siswa dengan cara menampilkan gambar bergerak dan suara, dan memberikan pesan untuk menstimulasi sikap dan emosi siswa. Dengan demikian, media audio visual sangat berguna untuk :

a) menarik perhatian siswa dalam belajar,

b) menumbuhkan motivasi, serta

c) merangsang kemampuan menyimpulkan pembelajaran dari sebuah video yang disajikan oleh guru.

Dengan segala fungsi dari media audio visual, media ini juga memiliki kelebihan dan kekuarangan. Menurut Fitria (2014) Kelebihannya yakni :

a) dapat digunakan secara klasikal,

b) dapat digunakan secara spontan,

c) dapat digunakan secara terus menerus,

d) dapat menampilkan objek yang bersifat berbahaya seperti bahan kimia,

e) materi menjadi lebih detil,

f) dapat dipercepat dan diperlambat.

Sebaliknya, media audio visual juga memiliki beberapa kelemahan yakni :

a) membutuhkan waktu untuk merevisi,

b) memerliukan biaya,

c) memerlukan keahlian, dan

d) semua peralatan harus lengkap karena jika ada yang kurang, maka video tidak bisa diputar. 


\section{Metode}

Dalam pelaksanaan pengabdian ini, tim pengabdi membutuhkan metode yang membantu proses pengabdian ini berjalan lancar. sesuai dengan judulnya, pengabdian ini menggunakan metode audio visual dengan alasan bahwa perlengkapan untuk menunjang metode ini sudah ada di SMA Islam Terpadu Al-Kamal NW. perlengkapan yang dimaksud berupa LCD yang digunakan untuk menampilkan materi ajar kepada siswa. Dalam melancarkan proses pengabdian, berikut langkah-langkah yang dilakukan oleh tim pengabdi.

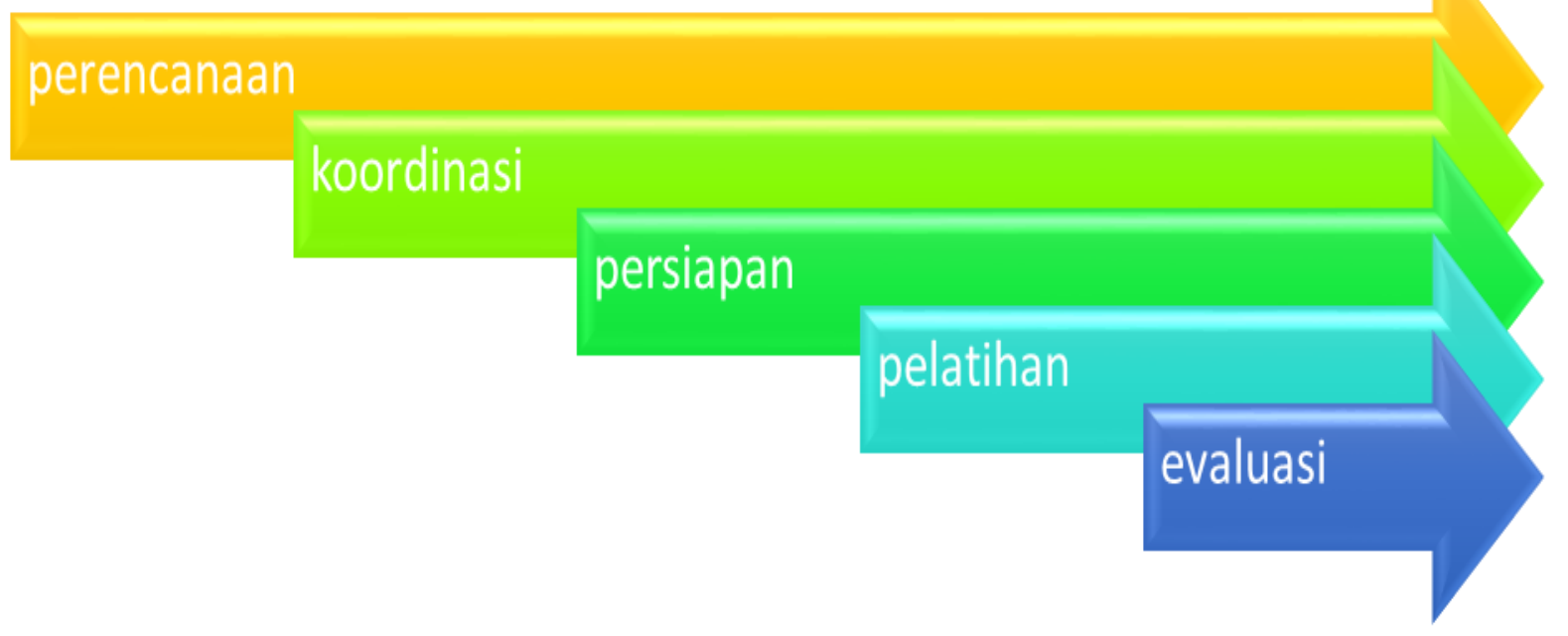

Gambar 1. Langkah-langkah pelaksanaan pengabdian

Langkah pertama yakni perencanaan. Pada tahap ini tim pengabdi melakuka perencanaan pengabdian mulai dari menentukan sasaran pengabdian, materi pengabdian, metode yang digunakan, dan tujuan pengabdian. Pada tahap kedua yakni tahap koordinasi. Tahap ini tim melakukan koordinasi dengan lembaga sasaran pengabdian serta meminta ijin guna melakukan pengabdian di lembaga sasaran dengan melakukan penandatangan kesepakatan kedua belah pihak. Dalam tahap ini juga, tim melakukan koordinasi dengan lembaga asal untuk mendapatkan ijin pengabdian sehingga nantinya berjalan lancar. tahap selanjutnya yakni persiapan. Pada tahap ini, tim melakukan persiapan baik itu berupa materi ajar dalam bentuk video dan power point untuk dipresentasikan kepada siswa di SMA Islam Terpadu Al-Kamal NW.

Langkah selanjutnya yakni pelatihan. Pada tahap ini, tim pengabdi melakukan pelatihan bahasa Inggris dengan menggunakan metode audio visual di ruang kelas selama tiga bulan. Langkah terakhir yakni evaluasi. Langkah ini merupakan penentu hasil pelatihan dimana setiap peserta akan diberikan ujian berupa tulis maupun lisan untuk memastikan mereka dapat menyerap materi dengan baik. 


\section{Pembahasan}

\section{1) Perencanaan}

Dalam tahap perencanaan semua tim berkumpul untuk membuat perencanaan seperti menentukan sasaran pengabdian, tujuan pengabdian, pembagian materi, metode yang digunakan, dan jangka waktu pengabdian .

Pada saat menentukan sasaran pengabdian, tim kami memiliki bebereapa alternative sasaran pengabdian yakni ke kelompok masyarakat tertentu, sekolah negeri dan sekolah swasta. Dari tiga alternatif ini, pilihan tim jatuh kepada sekolah swasta dengan pertimbangan bahwa sekolah swasta lebih membutuhkan SDM untuk meningkatkan kualitas pendidikan. Dengan demikian, kami sepakat untuk memilih SMA Islam Terpadu AI-Kamal NW yang berlokasi di Jl. Negara, Km. 15 Tibupling, kec. Narmada, Lombok Barat. Tujuan dari pengabdian ini adalah untuk meningkatkan kemampuan bahasa Inggris kelas III SMA IT ALKamal NW dengan pertimbangan mereka bisa melatih kembali adik kelas dan sebagai persiapan untuk menghadapi ujian berskala nasional.

Materi yang disajikan dalam pengabdian ini lebih cenderung kepada keterampilan berbicara karena saat ini SMA IT AI-Kamal NW sedang menggaungkan brand kemampuan bahasa Asing pada siswanya. Berikut pembagian materi untuk tiap tim.

Tabel 1. Pembagian materi ajar dan jadwal pengajaran

\begin{tabular}{llll}
\hline \multicolumn{1}{c}{ Nama dosen } & \multicolumn{1}{c}{ Materi } & \multicolumn{1}{c}{ Jadwal } \\
\hline Dr. Sutarman, M.Pd & 1. & Self- introduction & Meeting 1 \\
& 2. & Introducing others & Meeting 2 \\
& 3. & Greetings & Meeting 3 \\
\hline Dr. Zainudin & & & Meeting 4 \\
Abdussamad, M.Hum & 2. & Describing my self & Meeting 5 \\
& 3. & Describing friends & Meeting 6 \\
\hline Dr. Abdul Muhid, M.Pd & 1. & Simple present & Meeting 7 \\
& 2. & Present continuous & Meeting 8 \\
& 3. & Simple future & Meeting 9 \\
\hline Dr. Lela Rahmawati, & 1. & Parts of speech & Meeting 10 \\
M.Pd dan Wahyu Kamil & 2. & Types of sentence & Meeting 11 \\
Syarifaturrahman, M.Pd & 3. & Passive sentence & \\
\hline & & &
\end{tabular}

Meeting 12 


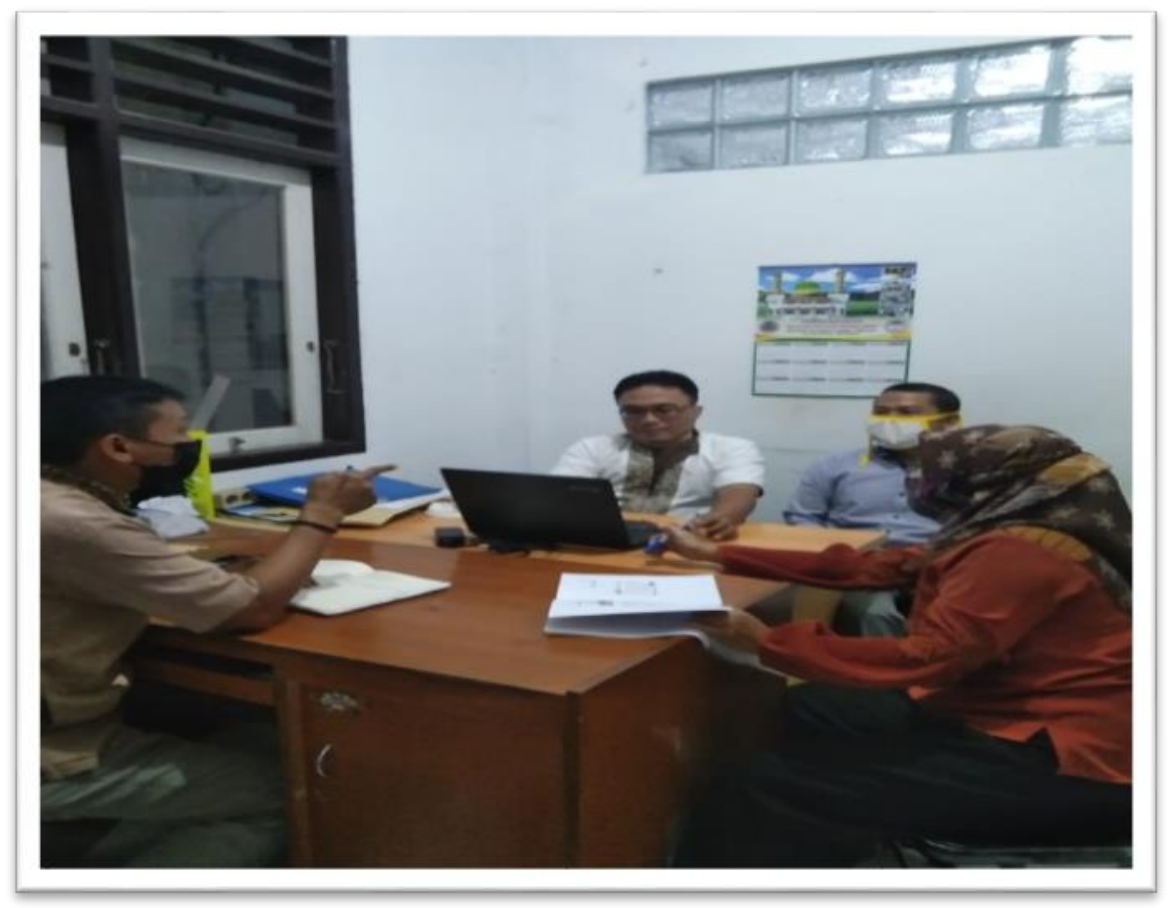

Gambar 2. Rapat perencanaan pengabdian oleh tim

\section{2) Koordinasi}

Setelah perencanaan terasa matang, tim melanjutkan dengan melakukan koordinasi dengan kepala sekolah SMA IT Al-Kamal NW untuk meminta izin melakukan pengabdian. Kami berkunjung ke lokasi dan bertemu dengan kepala sekolah. Pihak sekolah dengan senang hati menerima pengabdian kami dan menyediakan ruangan untuk digunakan sebagai ruang belajar. Selain itu, dia memberikan izin penggunaan LCD miliki sekolah sebagai media pembelajaran karena media tersebut sangat dibutuhkan untuk menunjang metode pengajaran kami.

\section{3) Persiapan}

Pada tahap persiapan, semua tim berkerja untuk mempersiapkan materi yang sudah dibagi ke dalam betook video maupun power point. Selain persiapan materi, tim juga mempersiapkan koordinasi terkait ijin dari kampus untuk melaksanakan pengabdian di luar kampus yakni di SMA Islam terpadu AI-Kamal NW. Setelah izin keluar, maka kami dapat melanjutkan pengabdian ini.

\section{4) Pelatihan}

Pada tahap ini, kami melakukan pelatihan kepada siswa SMA Islam Terpadu AlKamal kelas III. Kami melakukan pelatihan ini selama 12 kali pertemuan atau 3 bulan terhitung mulai bulan Maret-Mei 2021. Untuk menghasilkan output yang sesuai dengan 
tujuan awal yaitu untuk meningkatkan kemampuan berbicara siswa, maka kami dari tim pengabdi memilih beberapa materi yang sering digunakan dalam kegiatan sehari-hari. Yang pertama kami bagi menjadi dua bagian yakni tahap introduction. Tahap ini berisi tentang beberapa tema yang berkaitan dengan perkenalan diri dan orang lain. Tema ini dipilih karena sering digunakan dalam kegiatan sehari-hari, dimana para siswa sering bertemu dengan siswa lainnya antar kelas bahkan siswa baru. Dengan tujuan memantapkan kemampuan cara perkenalan dalam bahasa inggris, diharapkan siswa-siswa akan mengaplkasikannya dalam kegiatan sehari-hari.

Tema kedua yakni berkaitan dengan tata bahasa dasar dalam bahasa inggris seperti kelas kata, dan tenses. Pada tema ini, tim akan mengaitkan tata bahasa dasar ini dengan kegiatan sehari-hari sehingga akan mudah untuk memahami. Penekanan tata bahasa dasar yang dikolaborasikan dengan kegiatan sehari-hari ini bertujuan agar para siswa mampu berkomunikasi dengan baik sesuai dengan kaedah bahasa Inggris. Namun demikian, keterbatasan waktu menjadi kendala untuk memberikan pelatihan yang lebih intensif sehingga materi pelatihan disesuaikan dengan kebutuhan sehari-hari. Kami dari tim pengabdi berharap agar pelatihan ini akan dilanjutkan sehingga bisa memberikan hasil yang lebih baik bagi siswa-siswi SMA IT AI-Kamal NW. berikut jadwal pelatihan selama 3 bulan.

Tabel 2. Jadwal pelatihan tim pengabdi

\begin{tabular}{|c|c|c|c|}
\hline \multirow[t]{2}{*}{ Nama dosen } & \multirow[t]{2}{*}{ Materi } & \multicolumn{2}{|c|}{ jadwal } \\
\hline & & Bulan & Minggu ke- \\
\hline \multirow[t]{3}{*}{ Dr. Sutarman, M.Pd } & Greeting & Maret 2021 & I \\
\hline & Self-Introduction & & II \\
\hline & Introducing others & & III \\
\hline \multirow{3}{*}{$\begin{array}{l}\text { Dr. Zainudin } \\
\text { Abdussamad, } \\
\text { M.Hum }\end{array}$} & Asking hobby & & IV \\
\hline & Describing my self & April 2021 & I \\
\hline & Describing friends & & II \\
\hline \multirow{3}{*}{$\begin{array}{l}\text { Dr. Abdul Muhid, } \\
\text { M.Pd }\end{array}$} & Simple present & & III \\
\hline & Present continuous & & IV \\
\hline & Simple future & Mei 2021 & 1 \\
\hline \multirow{5}{*}{$\begin{array}{c}\text { Dr. Lela } \\
\text { Rahmawati, M.Pd } \\
\text { dan Wahyu Kamil } \\
\text { Syarifaturrahman, } \\
\text { M.Pd }\end{array}$} & Parts of speech & & II \\
\hline & Types of sentence & & III \\
\hline & Passive sentence & & IV \\
\hline & & & \\
\hline & & & \\
\hline
\end{tabular}


Gambar dibawah ini menunjukkan kegiatan pelatihan bahasa inggris yang dilakukan di dalam kelas yang terlihat dihadiri oleh siswa-siswa pada SMA Islam Terpadu AI-Kamal NW. Siswa terlihat antusias mengikuti pelatihan yang diadakan.

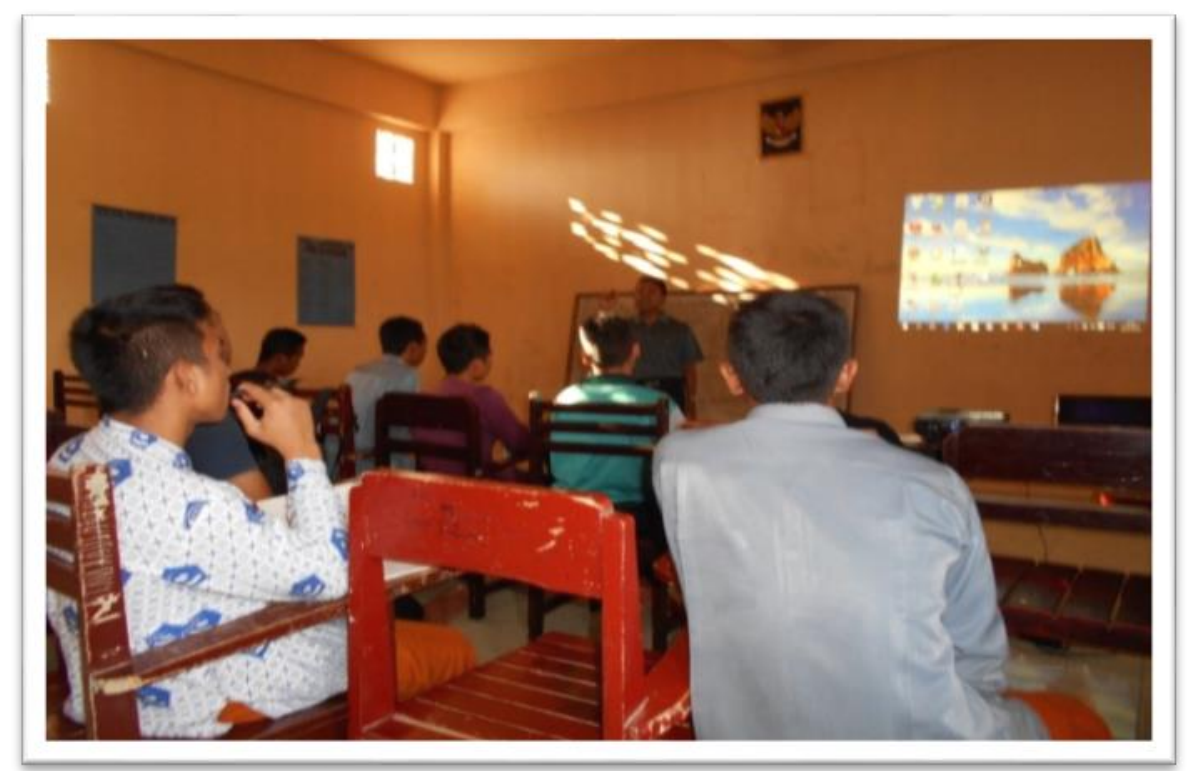

Gambar 3. Pelatihan bahasa Inggris

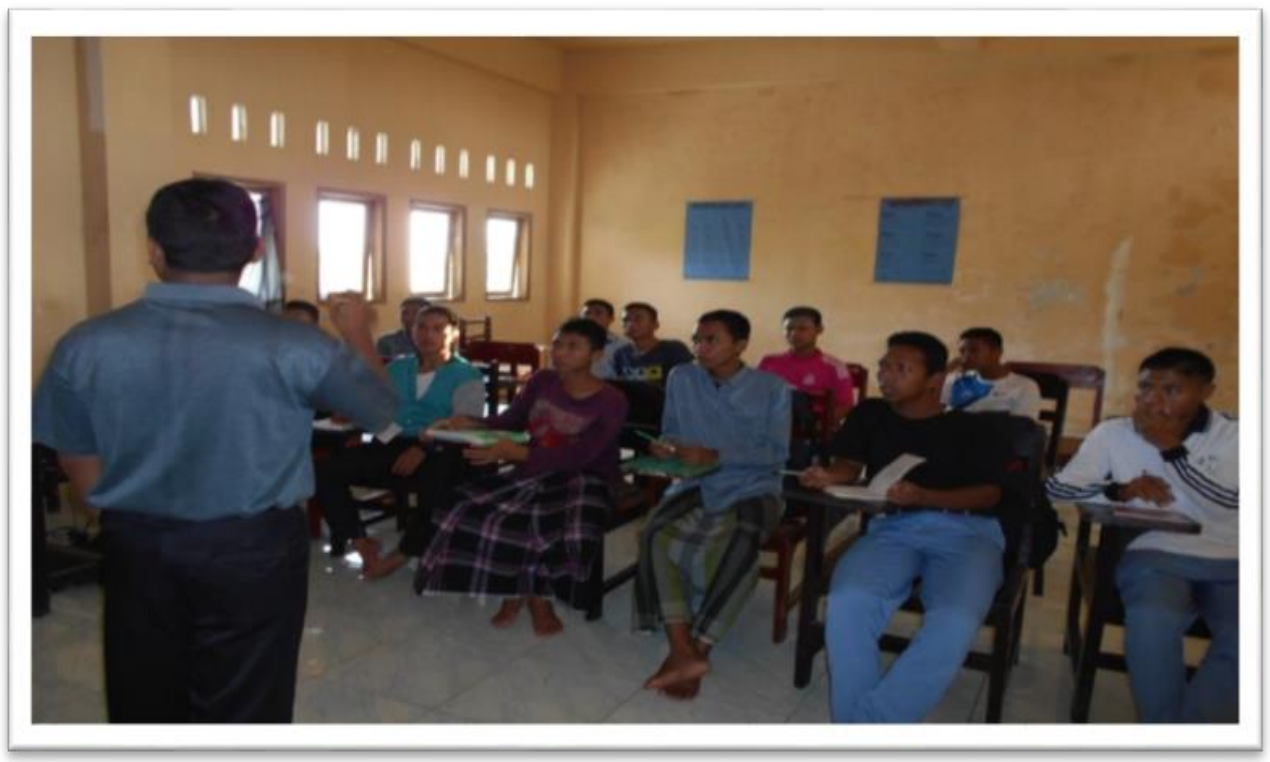

Gambar 4. Pelatihan Bahasa Inggris di SMA IT Al-Kamal NW 


\section{5) Evaluasi}

Tahap terakhir yakni evaluasi. Pada tahap ini kami melakukan evaluasi hasil terhadap peningkatan kemampuan peserta pelatihan bahasa Inggris yakni siswa SMA IT AlKamal NW. Tahap ini dilakukan dengan menggunakan oral test kepada siswa untuk mengetahui kemampuan berbicara (speaking) mereka, dan tes multiple choice untuk mengetahu tingkat kemampuan tata bahasa. Berikut hasi evaluasi terhadap siswa SMA IT AL-Kamal NW :

Tabel 3. Hasil evaluasi pelatihan bahasa inggris siswa SMA IT Al-Kamal NW

\begin{tabular}{|c|c|c|c|}
\hline \multirow[t]{2}{*}{ Nama siswa } & \multicolumn{3}{|c|}{ Hasil evaluasi pelatihan } \\
\hline & Pronunciation & Fluency & Tata bahasa \\
\hline Afrian Zulkarnaen & 75 & 73 & 80 \\
\hline $\begin{array}{l}\text { Agung Panji } \\
\text { Utomo }\end{array}$ & 73 & 75 & 79 \\
\hline Ahmat & 60 & 65 & 68 \\
\hline Al Zubaer & 65 & 68 & 70 \\
\hline Alpan Gipari & 80 & 79 & 75 \\
\hline Buyung & 65 & 67 & 64 \\
\hline $\begin{array}{l}\text { Juliawan Pratama } \\
\text { Putra }\end{array}$ & 76 & 74 & 71 \\
\hline Lalu Syiswandi & 68 & 65 & 64 \\
\hline M. Hapizin & 70 & 72 & 73 \\
\hline $\begin{array}{l}\text { M. Rodhian Nali } \\
\text { Arfan }\end{array}$ & 76 & 78 & 70 \\
\hline Mahyudin & 77 & 72 & 76 \\
\hline $\begin{array}{l}\text { Margono Eko } \\
\text { Saputro }\end{array}$ & 81 & 80 & 76 \\
\hline Mazid Alimi & 79 & 75 & 75 \\
\hline $\begin{array}{l}\text { Muhammad Ali } \\
\text { Isma }\end{array}$ & 80 & 79 & 76 \\
\hline Sahrul Azam & 81 & 76 & 79 \\
\hline $\begin{array}{l}\text { Sri Nurul } \\
\text { Handayani }\end{array}$ & 78 & 72 & 73 \\
\hline Zaenal Basri & 76 & 73 & 71 \\
\hline Rata-rata nilai & 74 & 73 & 72,94 \\
\hline
\end{tabular}


Dari hasil evaluasi diatas, dapat disimpulkan bahwa kemampuan siswa rata-rata berada diatas 70 yang artinya bahwa kemampuan mereka cuku bagus setelah melakukan pelatihan bahasa Inggris meskipun belum bisa dikatakan memuaskan. Namun, pelatihan ini perlu untuk dilanjutkan agar mereka memiliki keterampilan yang lebih baik sehingga kegiatan pelatihan bahasa inggris semacam ini pada SMA Islam Terpadu Al-Kamal NW dapat berkelanjutan.

Kegiatan yang sudah kami lakukan adalah yang pertama kami bagi menjadi dua bagian yakni tahap introduction berisi tentang beberapa tema yang berkaitan dengan perkenalan diri dan orang lain sehingga dalam siswa-siswa terbiasa menggunakan bahasa inggris dalam kesehariannya. Dimana para siswa sering bertemu dengan siswa lainnya antar kelas bahkan siswa baru. Dengan tujuan memantapkan kemampuan cara perkenalan dalam bahasa inggris, diharapkan siswa-siswa akan mengaplkasikannya dalam kegiatan sehari-hari. Tema kedua yakni berkaitan dengan tata bahasa dasar dalam bahasa inggris seperti kelas kata, dan tenses. Pada tema ini, tim akan mengaitkan tata bahasa dasar ini dengan kegiatan sehari-hari sehingga akan mudah untuk memahami.

\section{Kesimpulan}

Pelatihan kemampuan bahasa inggris merupakan kegiatan yang sangat perlu untuk dilakukan untuk mendukung daya saing masyarakat. Pelatihan di SMA IT AI-Kamal NW merupakan salah satu wujud partisipasi dosen dalam bentuk pengabdian. Hal ini perlu terus dilakukan agar siswa - siswa SMA IT AI-Kamal NW memiliki kemampuan yang mumpuni dalam berkomunikasi bahasa Inggris. Dengan hasil evaluasi diatas, Penggunaan metode audio-visual cukup memberikan semangat mereka dalam belajar sehingga mereka bisa menjawab soal dengan hasil yang cukup memuaskan. Harapan kami, semoga pelatihan ini dapat dilanjutkan sehingga akan memberikan dampak yang lebih besar kepada siswa SMA IT Al-Kamal NW.

\section{Ucapan Terimakasih}

Terimakasih diucapkan kepada Universitas Bumigora atas dukungannya untuk pengabdian ini dengan memberikan izin kepada tim untuk melaksanakan pengabdian. Ucapan terimaksih juga kami ucapkan kepada kepala sekolah SMA IT AI-Kamal NW yang memberikan kami kesempatan untuk melaksakan pengabdian di lingkungan sekolah. Selain itu, kepada pihak yang terkait seperti wakil kesiswaan SMA IT AI-Kamal NW yang telah menyediakan segala fasilitas untuk kelancaran pengabdian ini, kami ucapakan terima kasih. 


\section{Daftar Pustaka}

Abdussamad, Z., Sutarman, S., \& Syarifaturrahman, W. K. (2021). Peningkatan Keterampilan Bahasa Inggris Pemuda Karang Taruna Desa Mambalan Melalui Media Audio Visual. ADMA : Jurnal Pengabdian Dan Pemberdayaan Masyarakat, 1 (2), 79-84. https://doi.org/10.30812/adma.v1i2.1020

Anderson, R. (1994). Pemilihan dan Pengembangan Media Audio Visual. Grafindo Pers.

Fitria, A. (2014). penggunaan Media Audio Visual dalam Pembelajaran Anak Usia Dini. Cakrawala Dini, 5 (2).

Hermawan, \& H, A. (2009). Media Pembelajaran. UPI Press.

Rahmawati, L., \& Sutarman. (2021). Peningkatan Keterampilan Bahasa Inggris SMPN 19 melalui Model Triple P. ADMA : Jurnal Pengabdian Dan Pemberdayaan Masyarakat, 1 (2), 115-124.

Sanaky, A. H. (2011). Media Pembelajaran Buku Pegangan Wajib Guru dan Dosen. kaukaba. 
